\title{
PÓSTER 6
}

\section{SÍNDROME DE APNEA OBSTRUCTIVA DEL SUEÑO EN NIÑOS RESPIRADORES BUCALES TRATAMIENTO ORTOPÉDICO Y FONOAUDIOLÓGICO}

AUTOR: INSTITUCIÓN: PAIS:
Edward Frank Rafael Montalvo

Universidad Cruzeiro Do Sul

São Paulo-Brasil

\section{RESUMEN}

El Síndrome de Apnea Obstructiva del Sueño (SAHOS) es un disturbio de la respiración que ocurre durante el sueño y es caracterizado por prolongados episódios de obstrucción completa o parcial de las vias aéreas superiores, lo que interfiere en la ventilación y los padrones normales de sueño. En niños, el SAHOS se caracteriza por un continuo que va desde el RONQUIDO PRIMARIO (situación benigna de ronquido sin alteraciones fisiológicas y complicaciones asociadas), pasando por RESISTENCIA AUMENTADA DE LAS VIAS AÉREAS SUPERIORES un subtipo o una variación de SAHOS (caracterizado por períodos de aumento de la resistencia de las vias aéreas y de aumento de esfuerzo respiratorio durante el sueño; hasta finalmente SAHOS propiamente dicha asociados con ronquidos, fragmentación del sueño, somnolencia diurna excesiva y reducción de desempeño neurocognitivo), asociados también a una HIPOVENTILACIÓN OBSTRUCTIVA (asociados con hipercapnea).

Los pacientes respiradores bucales presentan una alta incidencia de presentar SAHOS (43\%), por lo que el tratamiento del síndrome de Respiración bucal es el más efectivo tratamiento para el SAHOS en niños. El tratamiento del paciente Respirador Bucal que presenta Apnea del Sueño, precisa de un manejo interdisciplinario realizado por el Pediatra, Otorrinolaringólogo, Odontólogo y Fonoaudiólogo.

Palabras clave: Síndrome de Apnea Obstructiva del Sueño, Respiración Oral

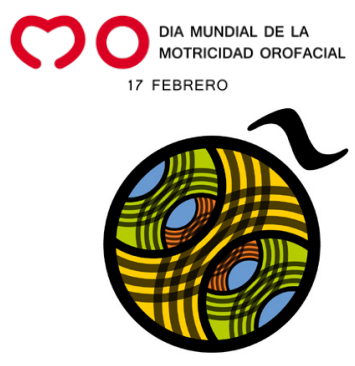

